\title{
TITLE: Recalcitrant lichen planopilaris and frontal fibrosing alopecia responding to tildrakizumab
}

\author{
Authors: \\ Dr Lara Trindade de Carvalho, MBBS \\ Dr Nekma Meah MBChB, MRCP (UK), MRCP (Derm) \\ Dr Dmitri Wall MB BCh BAO, MRCP (UK) MSc HIT \\ Professor Rodney Sinclair MBBS, MD, FACD
}

\begin{abstract}
Address:
Sinclair Dermatology, 2 Wellington Parade, East Melbourne, VIC, Australia
\end{abstract}

\section{Corresponding Author:}

Dr Lara Trindade de Carvalho

Email: lara.carvalho@sinclairdermatology.com.au

\begin{abstract}
Abbreviations:
Lichen planopilaris (LPP); frontal fibrosing alopecia (FFA); interleukin (IL); sun protection factor (SPF)
\end{abstract}

Keywords: Lichen Planopilaris, Frontal Fibrosing Alopecia, Tildrakizumab

This is the author manuscript accepted for publication and has undergone full peer review but has not been through the copyediting, typesetting, pagination and proofreading process, which may lead to differences between this version and the Version of Record. Please cite this article as doi: $10.1111 /$ dth.13694

This article is protected by copyright. All rights reserved. 


\title{
TITLE: Recalcitrant lichen planopilaris and frontal fibrosing alopecia responding to tildrakizumab
}

WORD COUNT: 753

\begin{abstract}
:
Lichen planopilaris (LPP) and frontal fibrosing alopecia (FFA) are lymphocytic, cicatricial alopecias. Clinically, LPP presents with multifocal patchy alopecia, while FFA, considered a variant of LPP, results in hairline recession. Frontal recession in FFA may progress as far as the mid-scalp and infrequently beyond. Treatment to arrest the inflammatory process can be challenging and response variable. We report a case of recalcitrant lichen planopilaris and frontal fibrosing alopecia demonstrating significant clinical improvement after four doses of the interleukin-23 (IL-23) monoclonal antibody tildrakizumab.
\end{abstract}

\section{MANUSCRIPT:}

A 73-year-old woman presented in 2013 with itchy scalp, of several years' duration. Premature menopause, post hysterectomy at 33 years of age, prompted hormonal replacement therapy for the last 20 years. Clinical examination revealed anterior hairline recession and occasional marooned hairs, with erythema and perifollicular hyperkeratosis of the anterior hairline (Fig. 1), occiput and vertex. Examination was otherwise unremarkable. Scalp biopsy revealed atrophic epidermis with a central follicle surrounded by a concentric rim of fibrosis, focal lichenoid change of the outer root sheath epithelium and scarring of the surrounding dermis, supporting a diagnosis of co-existent LPP and FFA.

Treatment with multiple medications, some concurrent, including: intralesional triamcinolone acetonide $5 \mathrm{mg} / \mathrm{mL}$ (intermittently for 58 months); multiple courses of prednisone $15 \mathrm{mg}$ daily (3 month tapering dose); infrared light (15 sessions); hydroxychloroquine $400 \mathrm{mg}$ daily (42 months); ciclosporin (18 months); tetracyclines including minocycline $50 \mathrm{mg}$ daily and doxycycline $100 \mathrm{mg}$ daily (each course of 6-months duration); tofacitinib $5 \mathrm{mg}$ daily (6 months); flutamide $50 \mathrm{mg}$ daily (3 months); minoxidil 1-2 mg daily (65 months); and dutasteride $0.5 \mathrm{mg}$ daily (14 months) (Tab. 1). Avoidance of sun protection factor (SPF) containing products above the eyeline was also advised in view of emerging evidence of its putative role in the genesis of FFA.1,2,3,4

Given the refractory nature of the condition and significant impact on quality of life, a trial of tildrakizumab (100 mg subcutaneously at week 0,4 and subsequently 12 weekly) was commenced after screening investigations, including viral hepatitis serology and 
QuantiFERON-TB Gold, were normal/unremarkable. Only minoxidil and dutasteride were continued after tildrakizumab initiation. Symptomatic improvement at week 16 review was maintained, and accompanied by objective clinical and dermoscopic examination at 28 weeks (Fig. 2) and 52 weeks (Fig. 3). There were no adverse effects and to date she remains in remission.

LPP is a lymphocytic cicatricial alopecia, characterised by areas of perifollicular violaceous erythema and keratotic plugs. The vertex is the most common area of the scalp involved. LPP has a female preponderance. Age of onset is most frequently between 40 and 60 years and there is no racial predilection. The aetiology of LPP is unknown, and its pathogenesis remains poorly understood. It is theorised that Langerhans cell-activated CD4 \& CD8+ T lymphocytes target an, as yet, unknown follicular antigen, leading to the destruction of hair follicles.5 FFA is considered a localized clinical variant of LPP that predominantly affects the frontoparietal margin of the scalp in postmenopausal women, typically with forehead skin atrophy and prominent veins, though eyebrows are often the first site to be affected. Trichodynia, characterised by scalp itch and/or burning is commonly described.6,7,8 While the aetiology remains a mystery, a number of theories have been proposed. One study showed a strong correlation between the incidence of thyroid disease and FFA, particularly hypothyroidism.9 A genome-wide association study has revealed four genomic loci: 2p22.2, 6p21.1, 8q24.22 and 15q2.1. Within the 6p21.1 locus, fine-mapping indicated that the association is driven by the $H L A-B^{*} 07: 02$ allele.10

Treatment options for LPP/FFA include: topical, intralesional and systemic corticosteroids; hydroxychloroquine; antiandrogens, including finasteride and dutasteride; topical and oral retinoids and minoxidil, though there is no robust evidence of a consistent, highly-effective strategy that prevents progression.3,11

Tildrakizumab is a fully-humanized monoclonal antibody that inhibits the p19 subunit of IL-23 and is approved by the Food and Drug Administration and European Medicines Agency for use in patients with moderate-to-severe psoriasis. Many inflammatory conditions have an up-regulation of the IL-23/IL-17 axis. There is evidence to support overexpression of IL-23/IL-17 in oral lichen planus and cutaneous lichen planus.12,13,14 The significant symptomatic improvement in this patient indicates that the IL-23/IL-17 pathway may also play a role in the pathogenesis of LPP/FFA, conditions that fall in the same umbrella of lichenoid diseases, and suggests that tildrakizumab may be a potential treatment option for these patients,. More robust, prospective clinical trials would be needed to support this.

In summary, we present the first case of refractory LPP and FFA responding to the antiIL-23 monoclonal antibody, tildrakizumab, with remission now maintained at 13 months.

\section{ACKNOWLEGMENTS:}


We would like to acknowledge Sun Pharmaceutical Industries Ltd. for compassionate supply of tildrakizumab.

\section{REFERENCES:}

1- Moreno-Arrones, O. M., Saceda-Corralo, D., Rodrigues-Barata, A. R. et al. 2019. Risk factors associated with frontal fibrosing alopecia: a multicentre case-control study. Clin. Exp. Dermatol. 44:404.

2- Aldoori, N. et al. (2016) Frontal fibrosing alopecia: possible association with leave-on facial skin care products and sunscreens; a questionnaire study. Br. J. Dermatol. 175, 762-767

3- Iorizzo M, Tosti A. Frontal fibrosing alopecia: an update on pathogenesis, diagnosis, and treatment. Am J Clin Dermatol. 2019 (in press). doi: 10.1007/s40257-019-00424-y.

4- Cranwell, W. C. and Sinclair, R. 2019. Sunscreen and facial skincare products in frontal fibrosing alopecia: a case-control study. Br. J. Dermatol. 180:943.

5- Tan KT, Messenger AG. Frontal fibrosing alopecia: clinical presentations and prognosis. Br J Dermatol 2009;160: 75-9

6- Tosti A, Piraccini BM, Iorizzo M, Misciali C. Frontal fibrosing alopecia in postmenopausal women. J Am Acad Dermatol 2005; 52:55-60.

7- S. Kossard, M.-S. Lee, and B. Wilkinson, "Postmenopausal frontal fibrosing alopecia: a frontal variant of lichen planopilaris," Journal of the American Academy of Dermatology, vol. 36, no. 1, pp. 59-66, 1997

8- Tosti A, Piraccini BM, Iorizzo M, Misciali C. Frontal fibrosing alopecia in postmenopausal women. J Am Acad Dermatol 2005; 52:55-60. 
9- Valesky E et al. Single-center analysis of patients with frontal fibrosing alopecia: evidence for hypothyroidism and a good quality of life. J Int Med Res 2018.

10- Tziotzios C, Petridis C, Dand N, et al. Genome-wide association study in frontal fibrosing alopecia identifies four susceptibility loci including HLA-B*07:02. Nat Commun 2019; 10. doi:10.1038/s41467-019-09117-w.

11- Racz E, Gho C, Moorman PW, Noordhoek Hegt V, Neumann HA. Treatment of frontal fibrosing alopecia and lichen planopilaris: a systematic review. J Eur Acad Dermatol Venereol 2013; 27: 1461-70.

12- Kolli, S.S.; Gabros, S.D.; Pona, A.; Cline, A.; Feldman, S.R. Tildrakizumab: A Review of Phase II and III Clinical Trials. Ann. Pharmacother. 2019, 53, 413-418

13- Lu R, Zeng X, Han Q et al. Overexpression and selectively regulatory roles of IL-23/IL17 axis in the lesions of oral lichen planus. Mediators Inflam. 2014; 2014: 701094.

14- Shen Z, Gao X, Ma L, et al. Expression of Foxp3 and interleukin-17 in lichen planus lesions with emphasis on difference in oral and cutaneous variants. Arch Dermatol Res 2014; 306: 441-446.

\section{TABLE}

Table 1: All medications, duration and reason for discontinuation.

\begin{tabular}{|l|l|l|}
\hline Medication & \multicolumn{1}{|c|}{ Duration } & \multicolumn{1}{c|}{ Response } \\
\hline $\begin{array}{l}\text { Intralesional triamcinolone } \\
5 \mathrm{mg} / \mathrm{mL}\end{array}$ & $\begin{array}{l}\text { Intermittent for 58 } \\
\text { months }\end{array}$ & Interrupted- Lack of efficacy \\
\hline Prednisone & $\begin{array}{l}\text { Multiple courses of 3- } \\
\text { months duration }\end{array}$ & Interrupted- Lack of efficacy \\
\hline Infrared light & 15 sessions & Interrupted- Lack of efficacy \\
\hline Hydroxychloroquine & 42 months & Interrupted- Lack of efficacy \\
\hline Cyclosporine & 18 months & Interrupted- Lack of efficacy \\
\hline $\begin{array}{l}\text { Tetracyclines (Minocycline, } \\
\text { Doxycycline) }\end{array}$ & $\begin{array}{l}\text { Each course of 6- } \\
\text { months duration }\end{array}$ & Interrupted- Lack of efficacy \\
\hline Tofacitinib & 6 months & Interrupted- Lack of efficacy \\
\hline
\end{tabular}




\begin{tabular}{|l|l|l|}
\hline Flutamide & 3 months & Interrupted- Lack of efficacy \\
\hline Minoxidil & 65 months & On going \\
\hline Dutasteride & 14 months & On going \\
\hline
\end{tabular}

This article is protected by copyright. All rights reserved. 


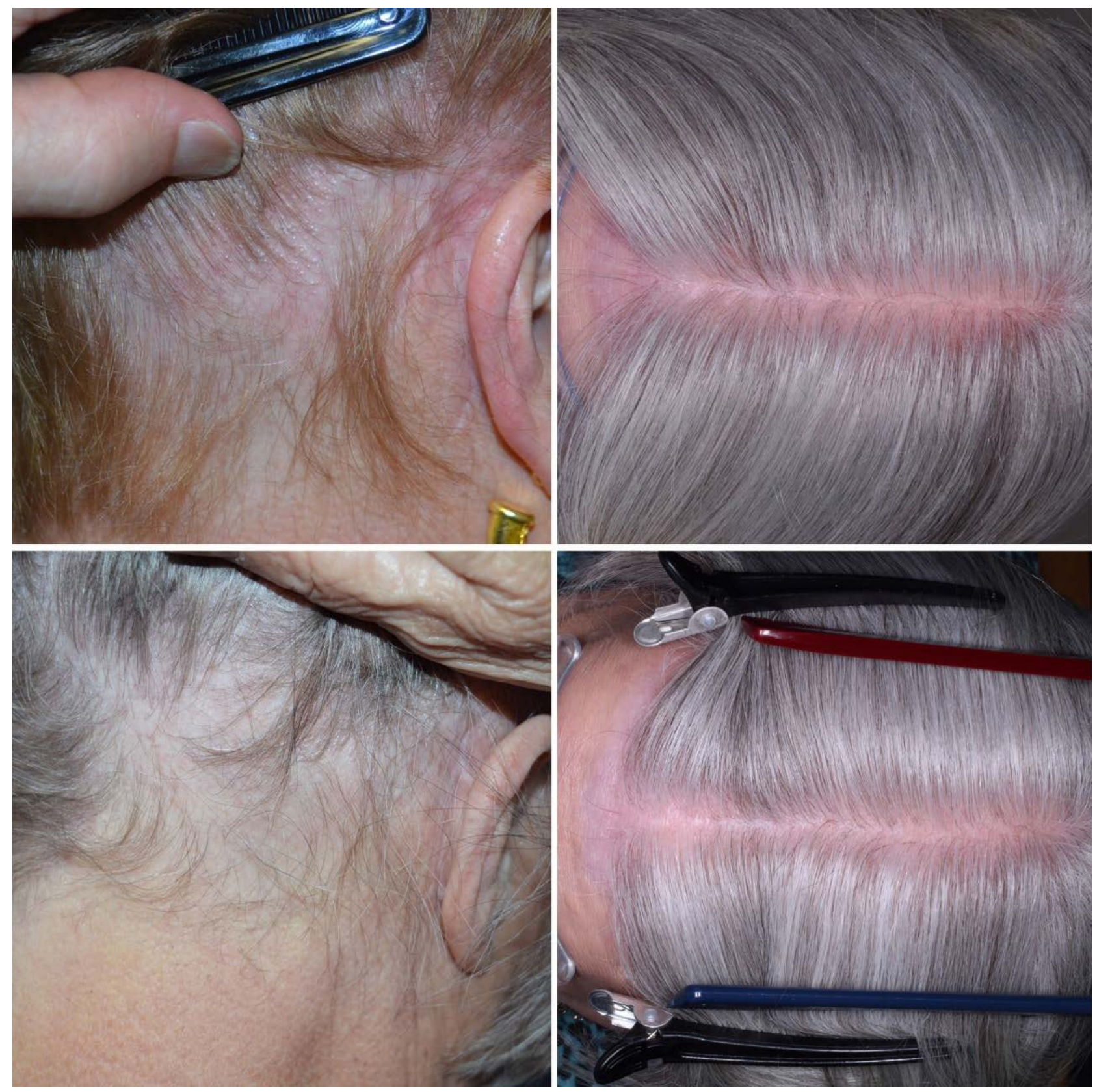

Figure 3: Right occiput (top left) and mid-scalp (top right) with marked erythema prior to tildrakizumab therapy. On the bottom, clinical improvement after six doses of tildrakizumab. 

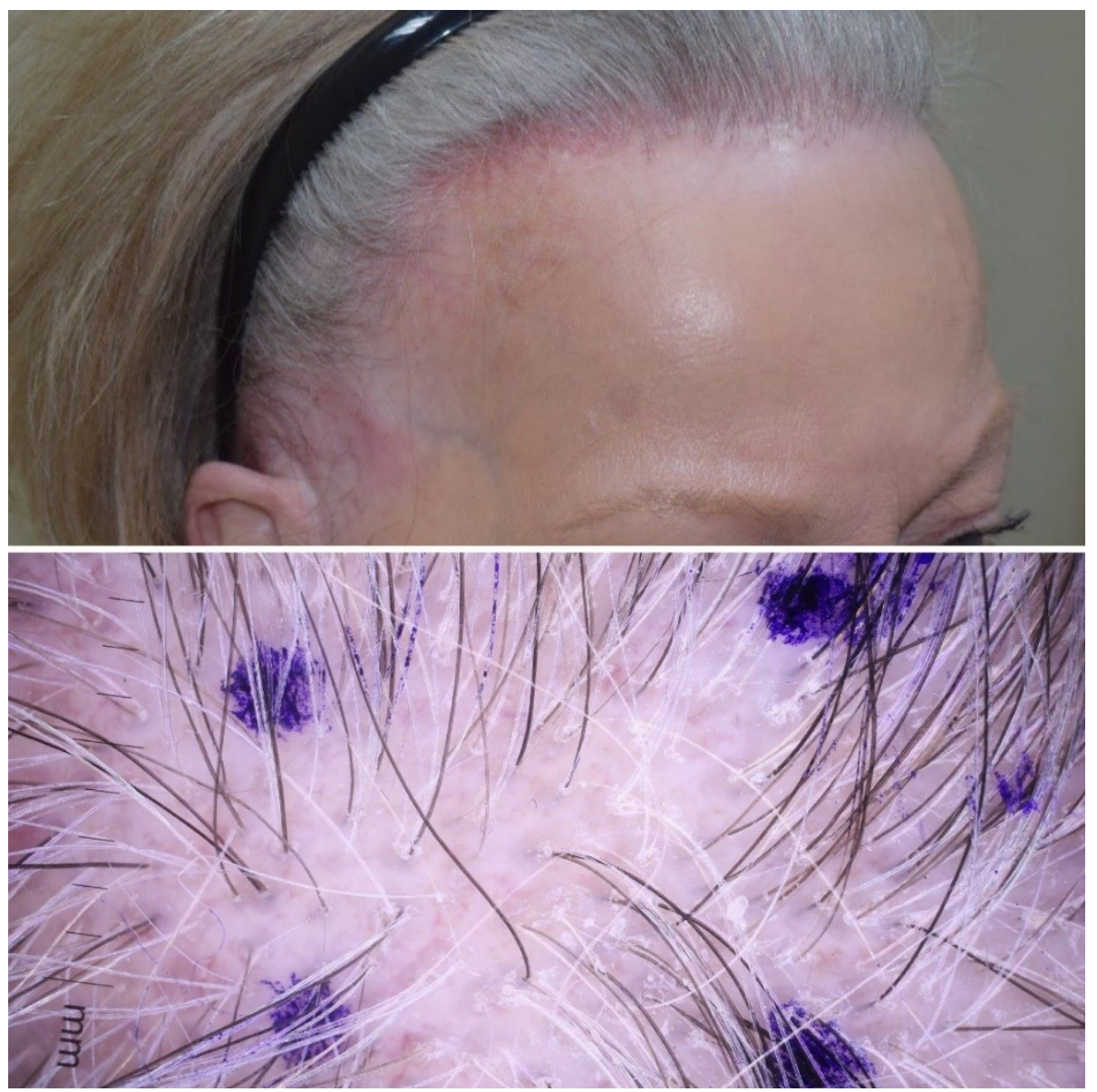

DTH_13694_FIGURE 1.jpg

This article is protected by copyright. All rights reserved. 

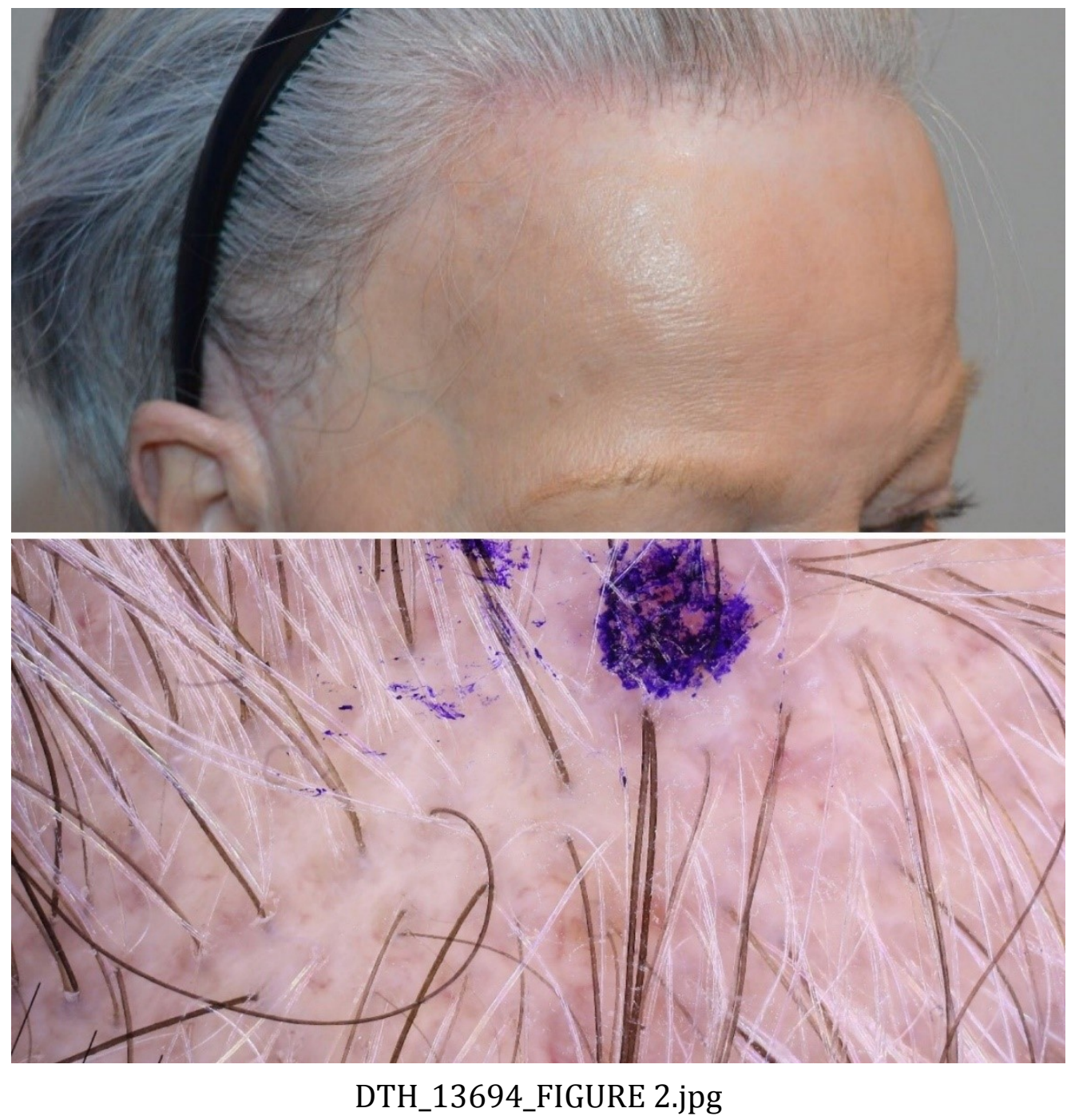

This article is protected by copyright. All rights reserved. 


\section{University Library}

\section{- M M N E R VA A gateway to Melbourne's research publications}

Minerva Access is the Institutional Repository of The University of Melbourne

Author/s:

Trindade de Carvalho, L;Meah, N;Wall, D;Sinclair, R

Title:

Recalcitrant lichen planopilaris and frontal fibrosing alopecia responding to tildrakizumab

Date:

2020-07-08

Citation:

Trindade de Carvalho, L., Meah, N., Wall, D. \& Sinclair, R. (2020). Recalcitrant lichen planopilaris and frontal fibrosing alopecia responding to tildrakizumab. DERMATOLOGIC THERAPY, 33 (4), https://doi.org/10.1111/dth.13694.

Persistent Link:

http://hdl.handle.net/11343/278559 